\title{
Glucocorticoid Attenuates Increases in Rat Brain Noradrenaline Turnover Induced by Intense Stress
}

\author{
RYOICHI NAKAGAWA, MASATOSHI TANAKA, YASUKO KOHNO, \\ YOSHISHIGE IDA, KENICHIRO IIMORI \\ AND NOBUYUKI NAGASAKI \\ Department of Pharmacology, Kurume University School of Medicine, \\ Kurume, 830 Japan
}

Received for publication May 26, 1983

\begin{abstract}
Summary: The effects of altered pituitary-adrenocortical function on contents of noradrenaline (NA) and its principal metabolite, 3-methoxy-4-hydroxyphenylethyleneglycol sulfate (MHPG-SO ${ }_{4}$ ) in brain regions of the rat exposed to acute intense stress (electric tail shock under conditions of immobilization) were investigated. Bilateral adrenalectomy significantly potentiated the stressinduced decreases in NA contents in the hypothalamus and thalamus, and the increases in MHPG-SO ${ }_{4}$ levels in the hypothalamus, amygdala, and thalamus. Supplementary administration of corticosterone attenuated both of these decreases of the amine and the increases of the metabolite. The results suggest that glucocorticoid secreted via the pituitary-adrenocortical axis has an inhibitory effect in part on the increased turnover of NA in some brain regions induced by acute intense stress.
\end{abstract}

Key words: noradrenaline - 3-methoxy-4-hydroxyphenylethyleneglycol sulfate - adrenalectomy - corticosterone - acute intense stress

\section{Introduction}

During acute intense stress, brain noradrenaline (NA) depletion has been shown to reflect strongly enhanced NA release which exceeds the amine synthesis (Bliss et al 1968; Stone 1973; Stolk et al. 1974). In our previous study (Nakagawa et aI. 1981), NA contents in rat brain regions decreased and were then maintained at the decreased levels during $180 \mathrm{~min}$ of electric tail shock under immobilization, conditions which were considered to be extremely intense. Levels of 3-methoxy-4-hydroxyphenylethyleneglycol sulfate (MHPG-SO ${ }_{4}$ ), a principal metabolite of NA (Schanberg et al. 1968) which reflects release of the amine in the rat brain (Korf et al. 1973; Sugden and Eccleston, 1971), increased progressively during the same period of stress.

The glucocorticoids, secreted via the pituitary-adrenocortical axis, plays an important role in an organism's mechanism for coping with environmental stress (Selye 1950). Some evidence indicates that variations in this system have significant effects on increased brain NA turnover of rats exposed to acute stress (Hedge et al. 1979; Vellucci 1977). The present experiment was undertaken to examine the possible role of glucocorticoids in the characteristic response of brain noradrenergic neurons to acute intense stress. We examined the effect of abolishing glucocorticoid secretion via adrenalectomy on the stress-induced changes in contents of NA and MHPG-SO ${ }_{4}$, and compared these find- 
ing with those obtained both with and without supplemental administration of cor ticosterone. The hypothalamus, amygdala, and thalamus were the brain regions chosen in the present study, because noradrenergic neurons in these three regions show rapid and marked response to the above stress or immobilization alone (Tanaka et al. 1982).

\section{Methods}

\section{Animals}

Male Wistar rats weighing 250-300 g were used in the experiment. Four rats were housed in a plastic cage $(210 \times 320 \times$ $135 \mathrm{~mm})$ at constant temperature $\left(24 \pm 1^{\circ} \mathrm{C}\right)$ under a $12 \mathrm{hr}$ light/dark cycle (on 0700 , off 1900). These animals were divided into three groups: sham-operated; adrenalectomized; and adrenalectomized plus corticosterone treated. These three groups were subsequently divided into two subgroups: non-stressed; and stressed. Each subgroup consisted of 14 rats. Bilateral adrenalectomy was performed on 84 rats by the dorsal approach under ether anesthesia. 42 rats received sham-operation. Adrenalectomized rats were given postoperatively $0.9 \% \mathrm{NaCl}$ solution and standard diet ad lib. Shamoperated animals were given food and water ad lib.

\section{Experimental Procedure}

The experiment was performed on the 10 th day after the operation. Half of the adrenalectomized rats were subcutaneously injected with $100 \mathrm{mg} / \mathrm{kg}$ of corticosterone (Sigma Chemical Co.) suspended in olive oil. The vehicle (olive oil) was subcutaneously injected in a volume of $0.2 \mathrm{ml} / 100 \mathrm{~g}$ weight into sham-operated and the remaining adrenalectomized animals. Two hours after the injection, each rat was immobilized with a wire mesh $(3 \times 3 \mathrm{~mm})$ and received an electric shock through an electrode apparatus attached to the tail for either 60 or $120 \mathrm{~min}$. The shock was de- livered using a constant voltage stimulator in square-wave pulses $(5 \mathrm{~Hz})$ for $5 \mathrm{sec}$ every $30 \mathrm{sec}$ at $15 \mathrm{~V}$ intensity ( $\mathrm{AC}$, about $2-3 \mathrm{~mA}$ ). The rats were sacrificed by decapitation in both the non-stressed and stressed groups immediately before and immediately following the stress, respectively.

\section{Tissue Preparation and Biochemical Deter. mination}

The brain was removed and rapidly dissected into discrete regions on an ice plate according to the method of Gispen et al. (1972). The brain regions dissected were: the hypothalamus, amygdala, and thalamus. Contents of NA and MHPG-SO in each brain region (two sample pooled) were determined by the method of Kohno et al. (1979). Trunk blood was collected and plasma corticosterone levels were determined based on the method of van der Vies (1961). All samples were stored at $-45{ }^{\circ} \mathrm{C}$ until assayed.

\section{Statistical Evaluation}

All statistical comparisons were made using analysis of variance (at least $\mathrm{P}<0.05$ ) with two factors, $i$. $e$. treatment (shamoperation, adrenalectomy, adrenalectomy plus corticosterone treatment) and time $(0$, $60,120 \mathrm{~min}$ ), and subsequently Turky posthoc pairwise comparisons $(\alpha=0.05)$, unless otherwise noted.

\section{Results}

Plasma corticosterone levels of shamoperated rats were markedly elevated by the combined stress of shock plus immobilization (the mean values \pm S. E. M. were: $41.0 \pm 1.0 \mu \mathrm{g} / \mathrm{dl}$ at $60 \mathrm{~min}$ and $41.8 \pm 1.4$ $\mu \mathrm{g} / \mathrm{dl}$ at $120 \mathrm{~min})$ as compared with nonstressed rats $(10.5 \pm 1.6 \mu \mathrm{g} / \mathrm{dl})$. Corticosterone levels were not detected in either non-stressed or stressed adrenalectomized rats. When adrenalectomized rats were 


\section{Hypothalamus}

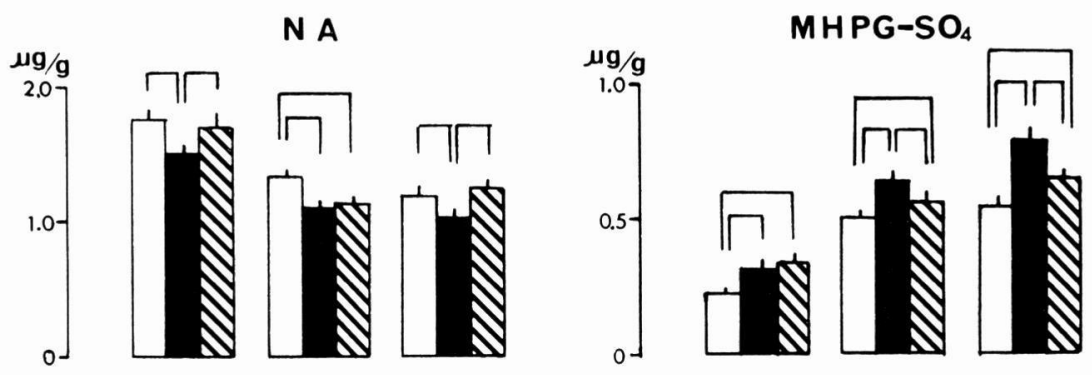

\section{Amygdala}
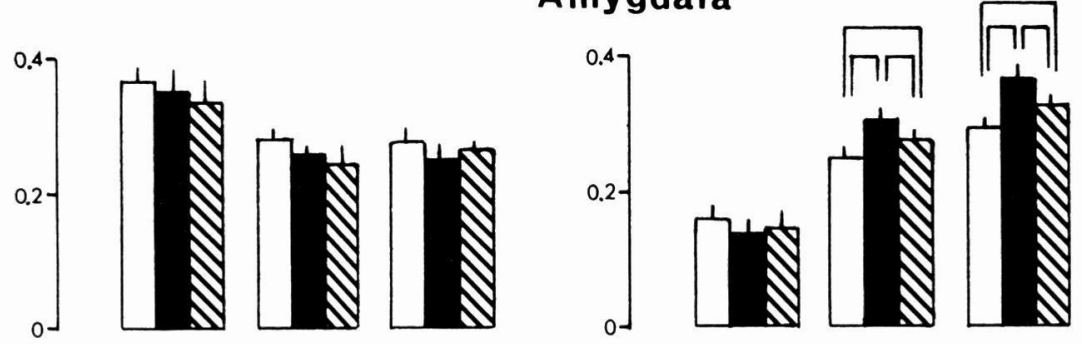

\section{Thalamus}
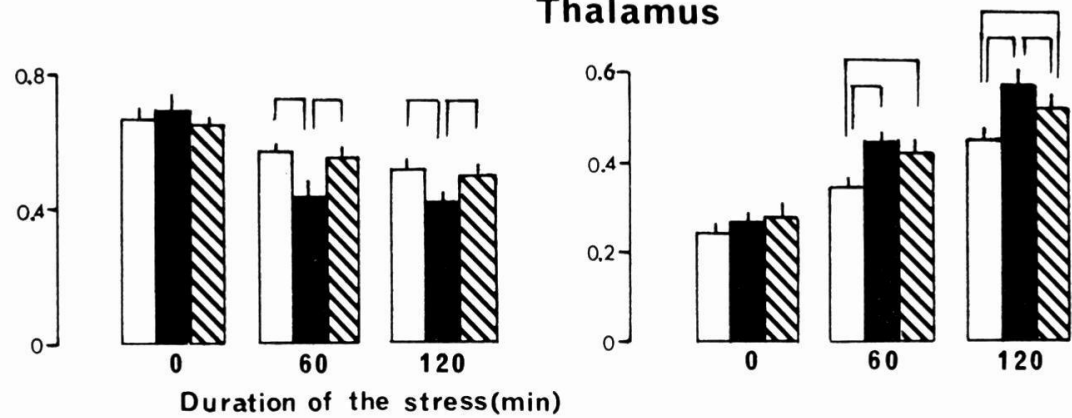

Fig. 1. Effect of altered pituitary-adrenocortical function on contents of NA and MHPG-SO ${ }_{4}$ in brain regions of rats exposed to acute intense stress.

Open columns are sham-operated groups, solid column adrenalectomized groups, and hatched columns adrenalectomized plus corticosterone-treated groups. Each values indicates the mean \pm S.E.M. $(\mathrm{N}=6-7)$. Statistically significant differences detween the groups are shown by the connecting bars $(\mathrm{P}<0.05)$.

treated with corticosterone $(100 \mathrm{mg} / \mathrm{kg})$, plasma corticosterone levels were much higher than those of sham-operated animals before the stress $(94 \pm 10.4 \mu \mathrm{g} / \mathrm{dl})$ and during the stress $(88.4 \pm 3.8 \mu \mathrm{g} / \mathrm{dl}$ at 60 $\mathrm{min}$ and $96.8 \pm 5.0 \mu \mathrm{g} / \mathrm{dl}$ at $120 \mathrm{~min})$.
Analysis of variance showed significant treatment effects on NA contents in the hypothalamus; $\mathrm{F}(2,52)=5.52 \mathrm{P}<0.01$ and thalamus; $\mathrm{F}(2,52)=6.05 \mathrm{P}<0.01$ and on MHPG- $\mathrm{SO}_{4}$ levels in the hypothalamus; $\mathrm{F}(2,52)=23.54 \mathrm{P}<0.01$, amygdala; $\mathrm{F}(2$, 
$53)=5.10 \mathrm{P}<0.01$, and thalamus; $\mathrm{F}(2$, 52) $=10.95 \mathrm{P}<0.01$.

As shown in Fig. 1 (0 min), adrenalectomy by itself significantly decreased NA content and increased MHPG-SO $\mathrm{SO}_{4}$ level in the hypothalamus, but not in the amygdala and thalamus. In the hypothalamus and thalamus, the stress caused significantly greater decreases in NA contents in adrenalectomized rats than those observed in shamoperated animals (60 and $120 \mathrm{~min}$ ). Stressinduced increases in MHPG-SO ${ }_{4}$ levels in adrenalectomized rats were significantly greater than those in sham-operated animals in the hypothalamus, amygadla, and thalamus (60 and $120 \mathrm{~min}$ ). The stress caused significantly smaller reductions of NA contents in the hypothalamus $(120 \mathrm{~min})$ and thalamus (60 and $120 \mathrm{~min}$ ) in adrenalectomized rats pretreated with corticosterone as compared with those without such treatment. Increases in MHPG-SO $\mathrm{SO}_{4}$ levels caused by the stress in adrenalectomized rats were significantly attenuated by the supplemental administration of corticosterone in the hypothalamus and amygdala (60 and $120 \mathrm{~min}$ ), and thalamus (120 min), however, these increases in MHPG-SO 4 levels were still significantly greater than those in shamoperated animals.

\section{Discussion}

Adrenalectomy, which abolished glucocorticoid secretion, potentiated increases in MHPG-SO $\mathrm{SO}_{4}$ levels in the hypothalamus, amygdala, and thalamus induced by acute intense stress consisting of electric tail shock under immobilization. Pretreatment with corticosterone, which replenished the glucocorticoids in adrenalectomized rats, attenuated the accelerated increases in the metabolite levels in the three brain regions examined. The stress-induced decreases in NA contents in the hypothalamus and thalamus were also potentiated by adrenalectomy and the accelerated NA reductions were reversed by supplemental administration of corticosterone. These findings suggest that corticosterone secreted via the pituitaryadrenocortical axis has an inhibitory role in part on enhanced NA turnover induced by stress in some brain regions of the rat. The present results are consistent with the finding of Endröczi et al. (1976) who demonstrated that stress-induced disappearances of tritiated NA in the hypothalamus and hippocampus of adrenalectomized rats were abolished by hydrocortisone implantation into the tubero-infundibular area.

Ruhmann-Wennhold and Nelson (1977) have indicated that markedly elevated plasma ACTH levels in adrenalectomized and stressed rats can be completely suppressed by dexamethasone treatment. ACTH has been shown to facilitate NA turnover in the intact rat brain (Biscardi and Naller, 1972; Javoy et al. 1968; Shen and Ganong, 1976). Together with these findings, it appears that the attenuating effect of corticosterone on stress-induced increases in brain NA turnover accelerated by adrenalectomy may result from decreased ACTH secretion via a negative feed back system. On the other hand, the suggestion that ACTH might provoke emotionality in the rat (DiGiusto et al. 1971; Weiss et al. 1969) raises the possibility that "anxious" rats (produced by increased circulation of ACTH under conditions of adrenalectomy) respond strongly to stress so that their NA turnover is markedly enhanced. Corticosterone treatment reduces $\mathrm{ACTH}$ secretion and so may relieve such a strong response in adrenalectomized animals. Interestingly, the present results showed that corticosterone possessed the attenuating effect on noradrenergic activity in the hypothalamus wich is a structure having important role in pituitary-adrenocortical function and emotions, as well as in the amygdala which has close anatomical connection with the hypothalamus (Henke, 1979). Moreover, we obtained the same effect of corticosterone on the thalamus, which regulates 
arousal level through relaying afferent sensory inputs.

Stress enhances amine synthesis in brain noradrenergic neurons, especially as Thierry et al. (1971) have suggested, via a process whereby newly synthesized NA is increased and selectively utilized in the rat brain during acute stress. Generally, NA concentration in the nerve terminals are regulated by balancing release and synthesis of the amine. We proposed the existence of a mechanism which supplies this available NA to protect NA stores from exhaustive depletion in the rat brain caused by continuously enhanced release of NA induced by acute intense stress (Nakagawa et al. 1981). Glucocorticoids may contribute in part to this supplementary regulation system. This idea is supported by the present finding that in the thalamus, corticosterone treatment reversed NA depletion potentiated by adrenalectomy without affecting MHPG $\mathrm{SO}_{4}$ level after $60 \mathrm{~min}$ of the stress.

Acknowledgements: The authors are grateful to Miss S. Takeda for her technical assistance and $\mathrm{Mr}$. Y. Noda, the Institute of Animal Experiment, Kurume University School of Medicine for his help with the adrenalectomy procedure. We wish to thank Dr. Gary B. Glavin, Associate Professor of the Department of Psychology, University of Winnipeg for his English editing of the manuscript.

\section{References}

Biscardi, A. M. and NAlLER, R. (1972). Turnover of dopamine and norepinephrine in hypothalamus of normal and hypophysectomized rats. Pharmac. Res. Commun. 4, 311-320.

Bliss, E. L., Ailion, J. and Zwanziger, J. (1968). Metabolism of norepinephrine, and serotonin and dopamine in the rat brain with stress. J. Pharmac. exp. Ther. 164, 122-134.

Diguisto, E.L., Caircross, K. and King, M.G. (1971). Hormonal influences on fear-motivated response. Psychol. Bull. 75, 432-444.

BNDRÖCzI, E., HrascheK, A., NyaKas, Cs. and Szabo, G. (1976). Effect of ACTH and its fragment on brain catecholamines in intact and adrenalectomized rats. Endokrinologie, 68, 51-59.

Gispen, W.H., Schotman, P. and Dekloet, E. R. (1972). Brain RNA and hypophysectomy: A topographical study. Neuroendocrinol. 9, 285296.

Hedge G. A., van Ree, J.M. and Versteeg, D. H. G. (1976). Correlation between hypothalamic catecholamine synthesis and ether stressinduced ACTH secretion. Neuroendocrinol. 21, 236-246.

HENKE, P. G. (1979). The hypothalamus-amygdala axis and experimental gastric ulcer. Neurosci Behav. Rev. 3, 75-82.

Javoy, F., Glowinski, J. and Kordon, C. (1968). Effect of adrenalectomy on the turnover of norepinephrine in the rat brain. Eur. J. Pharmac. 4, 103-104.

Kohno, Y., Matsuo, K., Tanaka, M. and Nagasaki, N. (1979). Simultaneous determination of noradrenaline and 3-methoxy-4-hydroxyphenylethyleneglycol sulfate in discrete brain regions of the rat. Analyt. Biochem. 97, 352358.

Korf, J., Aghajanian, G. K. and Roth, R. H. (1973). Stimulation and destruction of the locus coeruleus: Opposite effects on 3-methoxy4-hydroxyphenylglycol sulfate levels in the rat cerebral cortex. Eur. J. Pharmac. 21, 305310.

Nakagawa, R. Tanaka, M., Kohno, Y., Noda, Y. and NAGASAKI, N. (1981). Regional response of rat brain noradrenergic neurones to acute intense stress. Pharmac. Biochem. Behav. 14, 729-732.

RuhmanN-Wennhold, A. and Nelson, D. H. (1977). Plasma ACTH levels in stressed and nonstressed adrenalectomized rats. Ann. N. 'Y. Acad. Sci. 297, 498-507.

Schanberg, S. M., Breece, G., Schildkraut, J. J., Gordon, E. K. and Kopin, I. J. (1968). 3methoxy-4-hydroxyphenylglycol sulfate in brain and cerebrospinal fluid. Biochem. Pharmac. 17, 2006-2008.

Selye, H. (1950). The physiology and pathology of exposure to stress. ACTA INC., Montreal.

Shen, J. T. and Ganong, W.F. (1976). Effect of variations in adrenocortical function on dopamine- $\beta$-hydroxylase and norepinephrine in the brain of the rat. J. Pharmac. exp. Ther. 199, 639-648.

Stone, E. A. (1973). Accumulation and metabolism of norepinephrine in rat hypothalamus 
after exhaustive stress. J. Neurochem. 21, 589-601.

Stolk, J. M., Conner, R. L., Levine, S. and Brachas, J.D. (1974). Brain norepinephrine metaboilsm and shock-induced fighting behavior in rat: Differential effect on shock and fighting on the neurochemical response to a common foot shock stimulus. J. Pharmac. exp. Ther. 190, 193-209.

Sugden, R.F. and Eccleston, D. (1971). Glycol sulfate ester formation from $[14 \mathrm{C}]$ noradrenaline in brain and the influence of a COMT inhibitor. J. Neurochem. 18, 2461-2468.

Tanaka, M., Kohno, Y., Nakagawa, R., IDA, Y., TAKeda, S. and NAgASAKI, N. (1982). Timerelated differences in noradrenaline turnover in rat brain regions by stress. Pharmac. Biochem. Behav. 16, 315-319.
Thierry, A. M., Blanc, G. and Glowinski, J. (1971). Effect of stress on the disposition of catecholamine localized in various interneuronal storage forms in the brainstem of the rat. J. Neurochem. 18, 449-461.

VAN DER VIES, J. (1916). Individual determination of cortisol and corticosterone in a single small sample of peripheral blood. Acta. endocrinol. 38, 399-406.

Vellucci, S. V. (1977). The effect of ether stress and betamethasone treatment in various regions of the rat brain. Brit. J. Pharmac. 60, 601-605.

Weiss, J.M., Mcewen, B.S., Teresa, M., Silva, A. and KalKut, M.F. (1969). Pituitary-adrenal influences on fear responding. Science, 163, 197-198. 